\title{
Delphi4Delphi: first results of the digital archaeology initiative for ancient Delphi, Greece
}

Ioannis Liritzis ${ }^{1, *}$, George Pavlidis², Spyros Vosynakis ${ }^{3}$, Anestis Koutsoudis ${ }^{2}$, Pantelis Volonakis ${ }^{1}$, Nikos Petrochilos ${ }^{4}$, Matthew D. Howland ${ }^{5}$, Brady Liss ${ }^{5} \&$ Thomas E. Levy ${ }^{5}$

Digital media and learning initiatives for virtual collaborative environments are contributing to the definition of new (sub-)disciplines in archaeological and heritage sciences. New nomenclature and terminology is emerging such as cyber archaeology, cyber archaeometry, virtual worlds and augmented and immersive realities; and all of them are related to museums and cultural heritage-tangible, intangible or natural (Forte 2010; Liritzis et al. 2015).

The research project 'Digital Enterprise for Learning Practice of Heritage Initiative FOR Delphi' (Delphi4Delphi) aims to address many of these topics. In particular, it focuses on the educational, research and social implications of digital heritage. The ongoing work presented here highlights the first large-scale interdisciplinary cyber-archaeology project to make use of structure from motion (SfM) and CAVEcam measurements of heritage monuments and artefacts in Greece on any significant scale (Levy 2015).

Delphi was the most prestigious and authoritative oracle in the ancient world. Its reputation centred on the political decisions taken after consultation of the Oracle, especially during the period of colonisation of the Archaic period (c. eighth to sixth centuries BC), when cities sought her consent and guidance (Bommelaer 2015).

The main goal of the Delphi4Delphi project is to capture detailed 3D images of the major archaeological monuments at Delphi and artefacts in the Delphi Archaeological Museum

1 Department of Mediterranean Studies, Laboratory of Archaeometry, University of the Aegean, Rhodes 85100, Greece(Email: liritzis@rhodes.aegean.gr;p.volonakis@aegean.gr)

2 ATHENA-Research and Innovation Centre in Information, Communication and Knowledge Technologies, Panepistimioupoli Kimmerion, P.O. Box 159, 67100 Xanthi, Greece (Email: gpavlid@ipet.gr; akoutsou@ipet.gr)

3 Department of Product and Systems Design Engineering, University of the Aegean, Konstantinoupoleos 2, Hermoupolis, Syros 84100, Greece (Email: spyrosv@aegean.gr)

4 Ephoria of Antiquities in Phokis, Museum of Delphi, 33054 Delphi, Greece (Email: npetrochilos@hotmail.com)

5 Department of Anthropology and Center for Cyber-Archaeology and Sustainability-Qualcomm Institute, University of California, San Diego, Social Sciences Building Room 210 9500, Gilman Drive La Jolla, CA 92093-0532,USA (Email: mdhowlan@ucsd.edu; bliss@ucsd.edu; tlevy@ucsd.edu)

* Author for correspondence (Email: liritzis@rhodes.aegean.gr)

(C) Antiquity Publications Ltd, 2016

ANTIQUITY 90 354, e4 (2016): 1-6

doi:10.15184/aqy.2016.187 


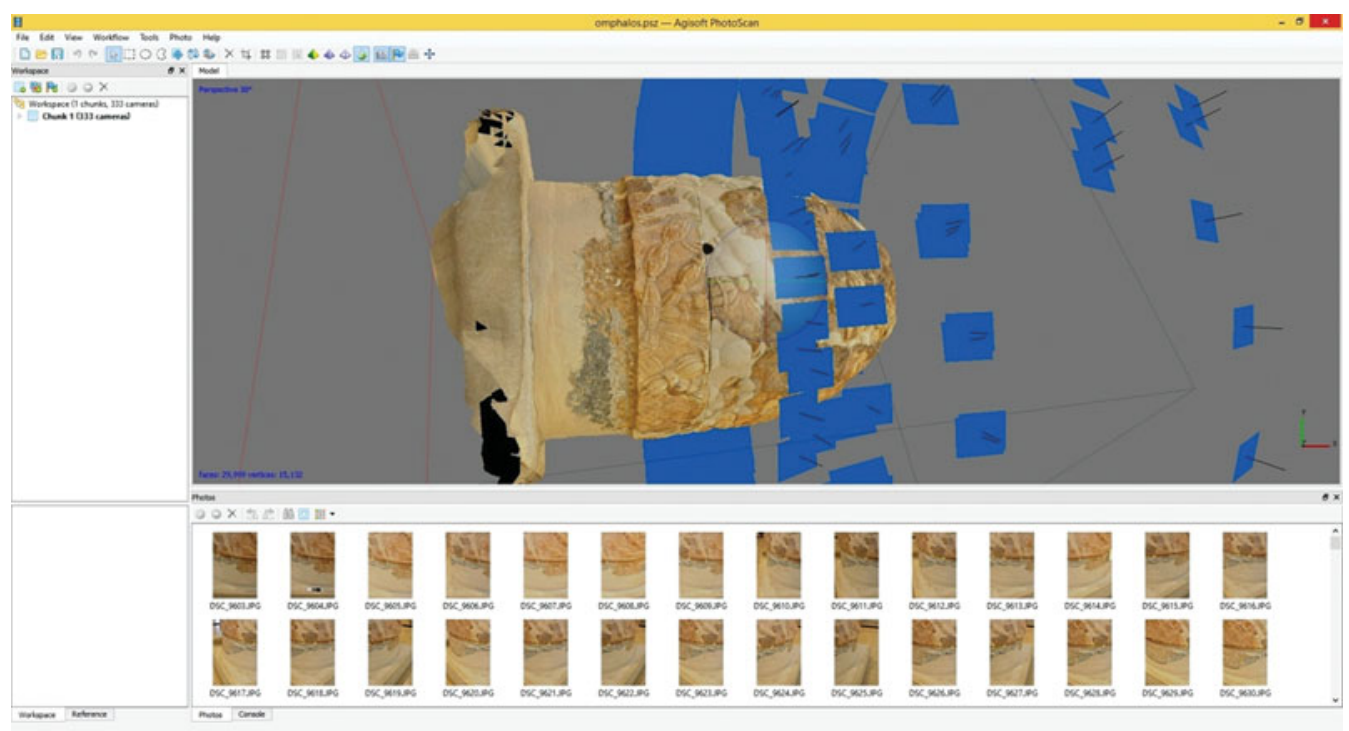

Figure 1. Structure from motion photography of the Omphalos, captured and cast into a 3D model.

in order to contribute to the $3 \mathrm{D}$ reconstruction of the sanctuary in support of research, conservation and tourism.

Two types of digital-photography-based recording systems were used in the 2015 season. The first method was SfM. This is a technique of spectral documentation (usually typical optical imaging), and refers to the process of making 3D structures from $2 \mathrm{D}$ image sequences. This constitutes recovering a scene's depth (the dimension that is not captured in a single typical 2D photo), and in recording it in a 3D data format (Pavlidis et al. 2007; Doneus et al. 2011; Koutsoudis et al. 2013) (Figures 1 \& 2).

The second system involved the use of the 3D CAVEcam stereo photography system, which produces $3 \mathrm{D}$-surrounding images of buildings and heritage sites. CAVEcam cameras capture $360 \times 180^{\circ}$ panoramic views (Figure 3-6). Both methods were used in a quick, non-invasive and affordable manner (DeFanti et al. 2009; Smith et al. 2013).

The monuments and artefacts recorded in 2015 as part of the Delphi4Delphi project include: the Temple of Apollo, the theatre, the gymnasium, the Sanctuary of Athena Pronaea (and the Tholos), the bronze charioteer and the marble sphinx, as well as decorative architectural elements of monuments such as those from the Treasury of the Siphnians.

The dataset generated during our first season totalled around 300GB. It will allow a detailed analysis of the ancient sanctuary and its material culture, including integration with archaeoastronomical studies of celestial phenomena prevailing at the time, the Oracle delivered her advice (Liritzis \& Castro 2013). The next stage of the research will include the use of balloons and drones to capture additional images of the site.

(C) Antiquity Publications Ltd, 2016 


\section{Delphi4Delphi}

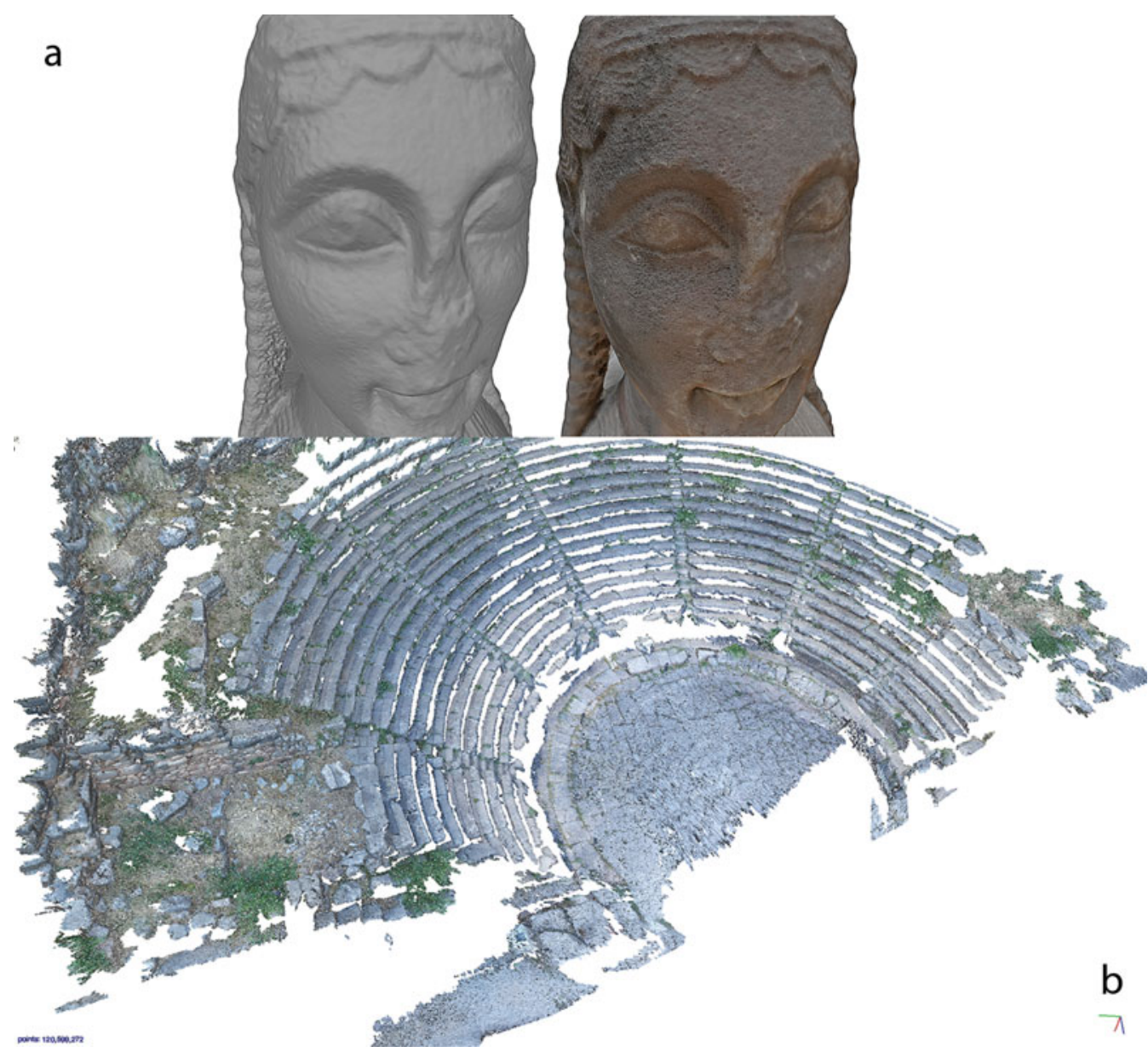

Figure 2. 3D geometry and textured models with structure from motion from the Delphi site and archaeological museum: a) the head of the sphinx; $b$ ) the dense point cloud of part of the theatre (about 120 million points measured). 
Ioannis Liritzis et al.

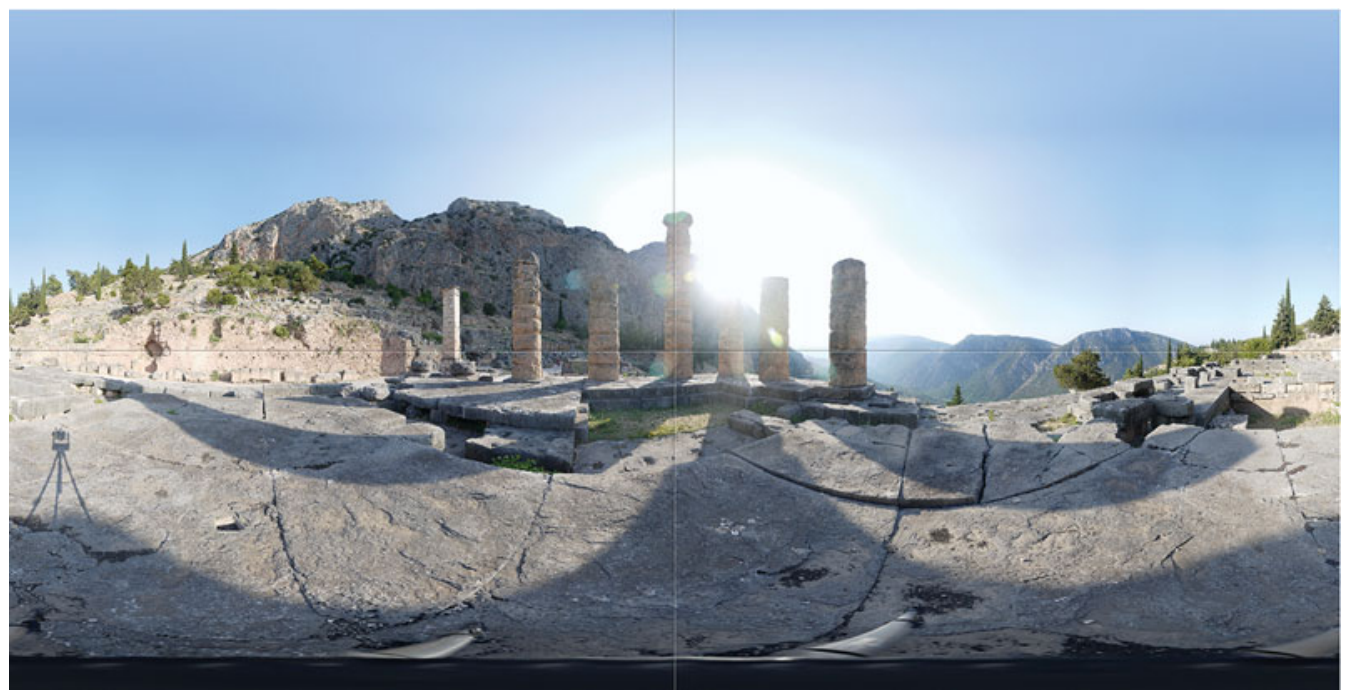

Figure 3. Stitched CAVEcam imagery from one camera of the Temple of Apollo.

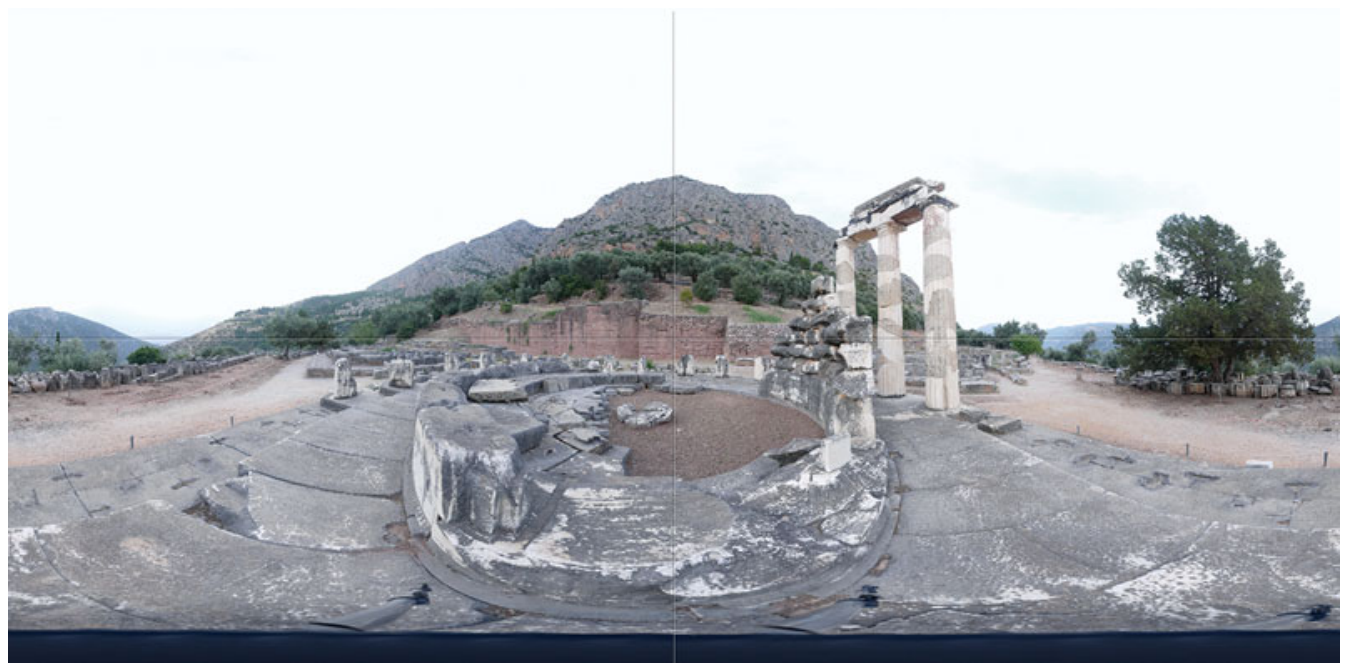

Figure 4. Stitched CAVEcam imagery from one camera of the interior of the Tholos.

C) Antiquity Publications Ltd, 2016 


\section{Delphi4Delphi}

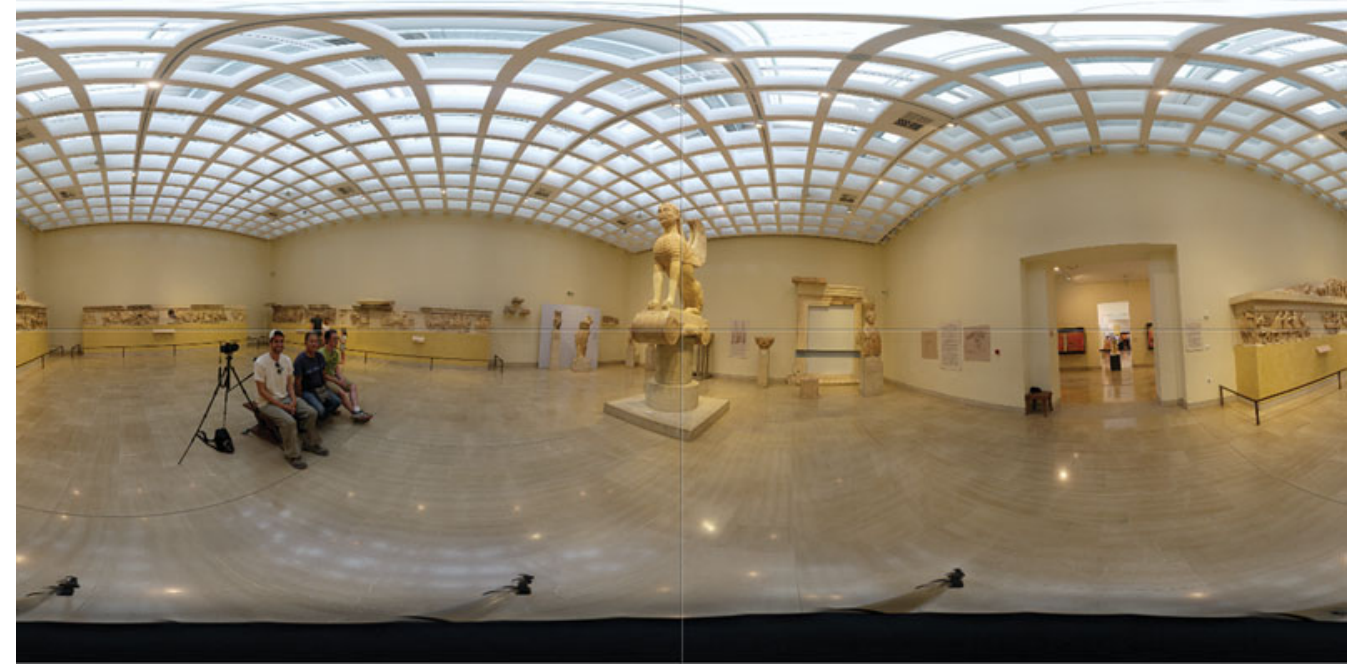

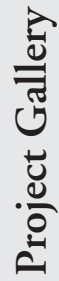

Figure 5. Stitched CAVEcam imagery from one camera of the Sphinx of Naxos.

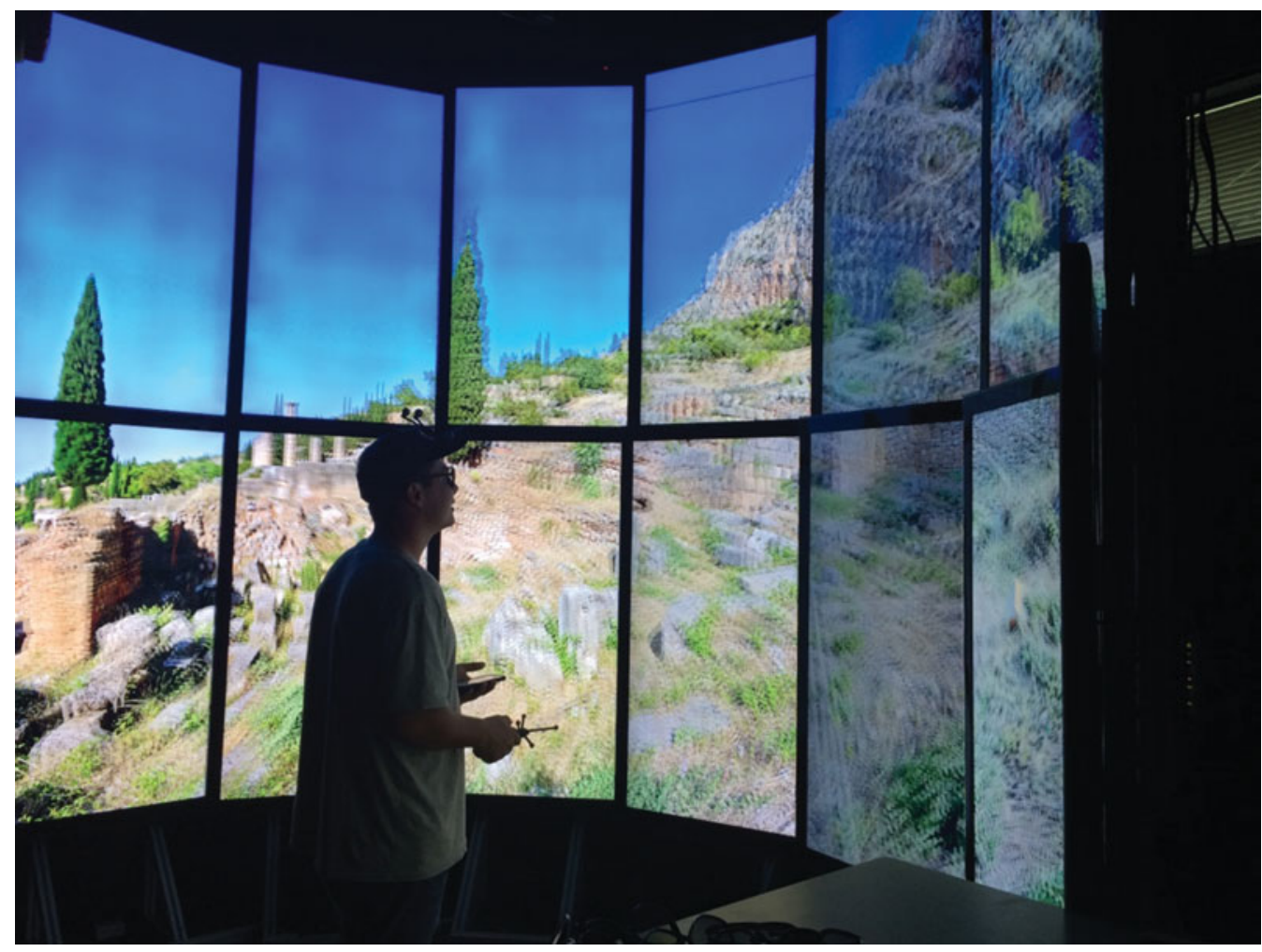

Figure 6. CAVEcam of Roman complex in the Qualcomm Institute, UCSD. 


\section{Acknowledgements}

We thank the Ministry of Culture and Sports, Greece, for providing the necessary permit, and A. Psalti for facilitating our work at Delphi.

\section{References}

Bommelaer, J.-F. 2015. Guide de Delphes, le site. Paris: Athènes.

Defanti, T.A., G. Dawe, D.J. Sandin, J.P. Schulze, P. Otto, J. Girado, F. Kuester, L. Smarr \& R. RAO. 2009. The StarCAVE, a third-generation CAVE and virtual reality OptIPortal. Future Generation Computer Systems 25: 169-78.

Doneus, M., G. Verhoeven, M. Fera, Ch. Briese, M. Kucera \& W. Neubauer. 2011. From deposit to point cloud - a study of low-cost computer vision approaches for the straightforward documentation of archaeological excavations, in Proceedings of the $23^{\text {rd }}$ International CIPA Symposium, Prague, Czech Republic. Available at: http://publik.tuwien.ac.at/files/ PubDat_206899.pdf (accessed 1 August 2016).

FORTE, M. 2010. Cyber archaeology (British Archaeological Reports international series 2177). Oxford: Archaeopress.

Koutsoudis, A., B. Vidmar \& F. Arnaoutoglou. 2013. Performance evaluation of a multi-image 3D reconstruction software on a low-feature artefact. Archaeological Science 40: 4450-56.
LEVY, T.E. 2015. The past forward. Biblical Archaeology Review (special issue): 81-87.

Liritzis, I. \& B. CASTro. 2013. Delphi and cosmovision: Apollo's absence at the land of the Hyperboreans and the time for consulting the oracle. Journal of Astronomical History and Heritage 16: 184-206.

LiRitzis, I., F.M. Al-OTAibi, P. VOLONAKIS \& A. Drivaliari. 2015. Digital technologies and trends in cultural heritage. Mediterranean Archaeology and Archaeometry 15: 313-32.

Pavlidis, G., A. Koutsoudis, F. Arnaoutoglou, V. Tsioukas \& C. Chamzas. 2007. Methods for 3D digitization of cultural heritage. Elsevier Journal of Cultural Heritage 8: 93-98.

Smith, N., S. Cutchin, R. KoOIma, R. Ainsworth, D. Sandin, J. Schulze, A. Prudhomme, F. Kuester, T. LeVy \& T. Defanti. 2013. Cultural heritage omni-stereo panoramas for immersive cultural analytics-from the Nile to the Hijaz, in Proceedings of the $8^{\text {th }}$ International Symposium on Image and Signal Processing and Analysis, Trieste, Italy: 552-57.

http://dx.doi.org/10.1109/ISPA.2013.6703802 